Article

\title{
Effect of Shear Resistance on Flexural Debonding Load-Carrying Capacity of RC Beams Strengthened with Externally Bonded FRP Composites
}

\author{
Guibing Li ${ }^{1, *}$, Aihui Zhang ${ }^{2}$ and Weiliang $\mathrm{Jin}^{3}$
}

1 Department of Management Science and Engineering, Shandong Institute of Business and Technology, Yantai 264005, China

2 College of Civil Engineering \& Architecture, Zhejiang University, Hangzhou 310058, China; E-Mail: zah@zju.edu.cn

3 Ningbo Institute of Technology, Zhejiang University, Ningbo 315100, China;

E-Mail: Jinwl@zju.edu.cn

* Author to whom correspondence should be addressed;

E-Mail: liguibing@zju.edu.cn or leegb@sina.com; Tel.:+86-535-690-3575.

Received: 8 February 2014; in revised form: 29 April 2014 / Accepted: 4 May 2014 /

Published: 13 May 2014

\begin{abstract}
Debonding failure is the main failure mode in flexurally strengthened reinforced concrete beams by externally bonded or near surface mounted fibre reinforced polymer (FRP) composites. It is believed that FRP debonding will be initiated if the shear stress on the concrete-FRP interface reaches the tensile strength of concrete. However, it was found through experimental and analytical studies that the debonding mechanism of FRP composites has the potential of shear failure in combination with debonding failure. Moreover, the shear failure probably influences the debonding failure. Presently, there are very little experimental and analytical studies to investigate the influence of shear resistance of reinforced concrete (RC) beam on FRP debonding failure. The current study investigates and analyzes the effect of shear resistance on FRP debonding failure based on test results. The analytical results show that the shear resistance of $\mathrm{RC}$ beam has a great effect on flexural debonding load-carrying capacity of FRP-strengthened RC beam. The influence of shear resistance on flexural debonding load-carrying capacity must be fully considered in flexural strengthening design of RC beams.
\end{abstract}


Keywords: reinforced concrete (RC) beam; carbon fiber reinforced polymer (CFRP)-strengthened; shear resistance; flexural debonding load-carrying capacity

\section{Introduction}

Debonding failure is the dominant failure mode in flexurally fiber reinforced polymer (FRP)-strengthened reinforced concrete (RC) beams by externally bonded or near surface mounted FRP composites. According to initial debonding position, debonding failure is classified into two types: end debonding and intermediate crack induced debonding (IC debonding). The intermediate cracks are mainly referred to as the critical flexural crack and flexure-shear crack [1]. End debonding failure can be prevented by ensuring effective bond length of FRP composites [2-6]. Furthermore, some fracture mechanics analyses confirmed that the extension of bond length beyond effective bond length has no effect on debonding capacity [7-10]. However, IC debonding failure cannot be easily overcome. Kim and Harris conducted a statistical analysis of failure modes on 230 FRP-strengthened RC beams by externally bonded FRP composites. The statistical results show that about $81.7 \%$ of the beams failed by FRP debonding; $9.6 \%$ of the beams failed by cover delamination [11]. FRP debonding together with concrete cover delamination are the main failure mode in flexurally FRP-strengthened RC beams. Over the past decade, considerable experimental and analytical studies have been carried out to investigate IC debonding failure [11-22]. The experimental variables against IC debonding failure include concrete strength, amount of FRP reinforcement, effective bond length, surface preparation of the concrete substrate, sustained load level (or damage level) on RC beam at bonding FRP composites, allowable tensile strain of FRP reinforcement and anchorage methods for FRP composites, etc.

To prevent debonding failure, numerous debonding criteria and effective bond length models have been proposed. These criteria and models can be classified into three distinct categories: allowable tensile strain in FRP composites based on the single-shear test on FRP-to-concrete joints [11,14,23-29], shear stress limitation on the FRP-concrete interface [30-33], and fracture mechanics based models [7-10,24,27,34,35].

With extensive experimental investigations having been conducted on the flexural behavior of RC beams with externally bonded FRP composites, a noteworthy problem regarding the debonding mechanisms had emerged that the debonding failure is the potential of shear failure in combination with debonding failure [36]. It was found in experimental investigation that the width of critical shear-flexure crack and the relative vertical displacement between the two halves of this crack that are related with the shear resistance of $\mathrm{RC}$ beam have effect on debonding failure of $\mathrm{RC}$ beams with externally bonded FRP composites [37-43]. However, there are very limited experimental and analytical studies to examine the influences of shear resistance of RC beam on debonding failure.

It appears that ensuring adequate shear resistance of the beam must be considered as the priority in flexural strengthening design. The objective of this study is to investigate this issue according to corresponding test results. 


\section{Existing Experimental Findings and Conclusions in the Literature}

Garden et al. [37,38] carried out four points bending and cantilever loading tests to investigate the influence of shear span/depth ratio, FRP plate anchorage length, and additional plate end anchorage on ultimate capacities and failure modes of reinforced concrete beams externally strengthened with bonded FRP plates. The main failure mode was FRP debonding with partial cover separation. The debonding characteristic is that a tributary crack formed adjacent to the main crack, forming a triangular shape bounded by the main crack, the tributary crack and the soffit of the beam. Opening-up of the main crack at beam soffit level was associated with the formation of relative vertical displacement at the tip of the tributary crack between the two halves of the main crack. The relative displacement became more pronounced with increasing applied load on the beam. Plate debonding propagated away from the tip of tributary crack to FRP plate end.

Rabinovitch and Frodtig [39] experimentally investigated the debonding failure triggered by edge effects, the stress concentration arisen near the edge of FRP strip, and the means for prevention of debonding failure. The debonding failure was triggered by the formation of critical flexure-shear crack at the shear span. The flexure-shear crack was usually associated with discontinuity in the vertical deflections of beam sections left and right of the cracked section. The interfacial delamination was initiated at the tip of the flexure-shear crack and propagated toward the support.

Pham and Al-Mahaidi [40,41] carried out a testing program including 18 rectangular reinforced concrete beams to investigate their failure mechanisms. The test varaibles are the carbon fiber reinforced polymer (CFRP) bond length, the number of plies, the area of tension reinforcement, the amount of shear reinforcement, and the concrete cover. The main failure mode was FRP laminates debonding. The critical flexural-shear crack under the loading point initiated the delamination of FRP laminates from the concrete substrate as the result of the high tensile force in FRP laminates and the vertical movement near its tip. More rotation was observed, the left part of the beam in the shear span tried to rotate to the right but it was held back by the FRP laminates. This leaded to the appearance of debonding cracks near the tip.

Yang et al. [43] employed four-point bending on flexurally strengthened RC beams externally bonded CFRP sheets with different bond length and U strip anchor at the laminate end to investigate the flexural debonding load-carrying capacity and debonding modes. It was found that the critical shear-flexure crack near the loading point was opening up gradually with the increasing of applied load. When the applied load reached a certain level, debonding occurred at the tip of the critical crack. Moreover, the shear span of the beam rotated significantly round the critical section. CFRP laminates debonded and propagated towards the direction of decreasing moment.

To verify the influence of relative vertical displacement on FRP debonding failure, Yao et al. [44] and Pan et al. $[45,46]$ carried out experimental studies to investigate the effect of relative vertical displacement on FRP debonding. Their test results showed that the relative vertical displacement has great effect on the load-carrying capacity of the test members.

All the above experimental results have the same finding that the debonding of FRP laminates initiated at or near the tip of the main crack (or the tributary crack) and a relative vertical displacement developed between the left and right section of the main crack. For debonding induced by a flexural crack, the crack widening is the driving force for the debonding. The widening of the crack is also 
more important than the relative vertical displacement in the debonding failure induced by critical flexural-shear crack [47].

\section{Experimental Programs}

Zhang et al. [42] tested $16 \mathrm{RC}$ beams flexural-strengthened with externally bonded FRP sheets under four points bending, these beams were divided into four series A1, A2, B1, and B2, respectively. The test variables include the sustained load level on RC beams at bonding FRP sheets, the amount of FRP sheets, and the amount of tension rebar, respectively. The main objective of this experimental study was to investigate the effect of sustained load level on the flexural performance of FRP-strengthened RC beams.

Li et al. [48] carried out experimental study by three-point bending 6 FRP-strengthened RC beams which divided into two series $\mathrm{C} 1$ and $\mathrm{C} 2$. Test variables are sustained load level on RC beams at bonding FRP sheets, amount of FRP sheets, and anchorage of FRP sheets at beam-column joint. The main purpose of the test was to investigate the flexural performance of beam section at negative moment region strengthened by bonding FRP sheets. The details of all tested specimen by Zhang et al. [42] and Li et al. [48] are listed in Table 1; Material properties are listed in Table 2.

The soffit of the beam to bond CFRP laminate was firstly ground and cleaned to ensure good bonding. Then loads were applied on the test beams to the desired preload level. With maintaining the load, on the clean and flat surface, primer, epoxy, and CFRP laminates were applied in sequence. After the epoxy resin had been completely cured, additional loads were applied up to the failure of the beam.

In addition to the main objectives in the experimental studies by Zhang et al. [42] and Li et al. [48], the debonding process and characteristics were also investigated as one of the main goals. For the convenience of bonding FRP sheets and ensuring bonding quality, reverse loading was used in the experimental tests, as shown in Figure 1.

Figure 1. Test-setup of A2 and B2 series.
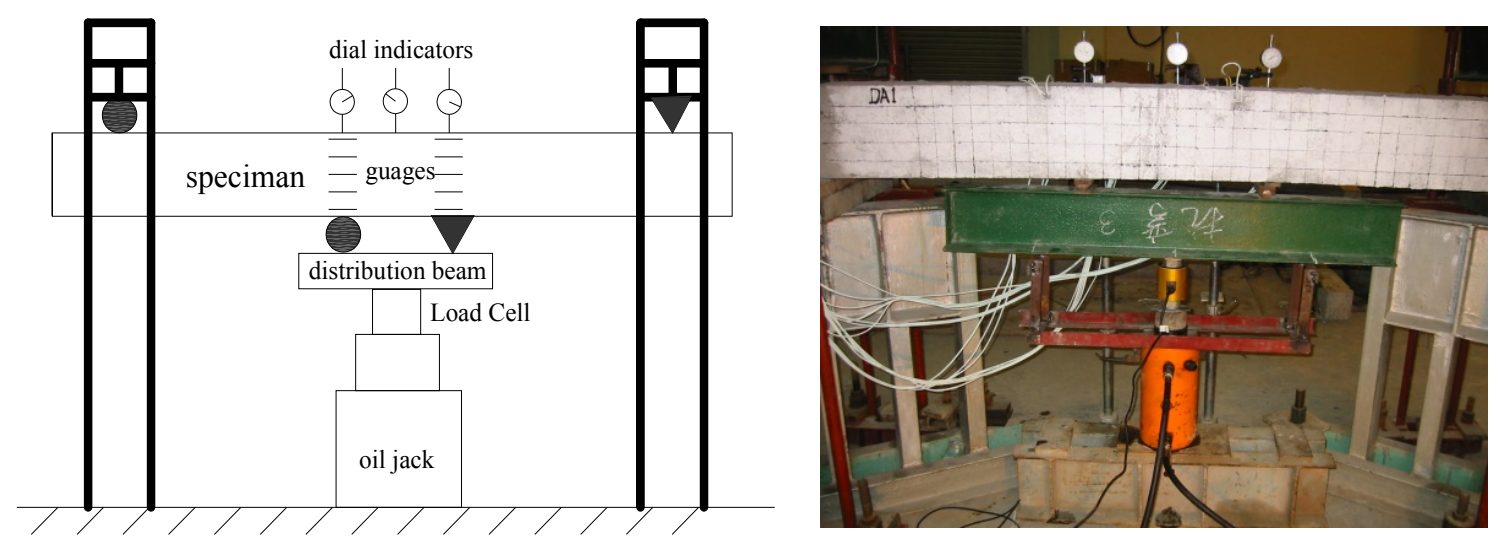
Table 1. Dimensions of specimen and reinforcement materials.

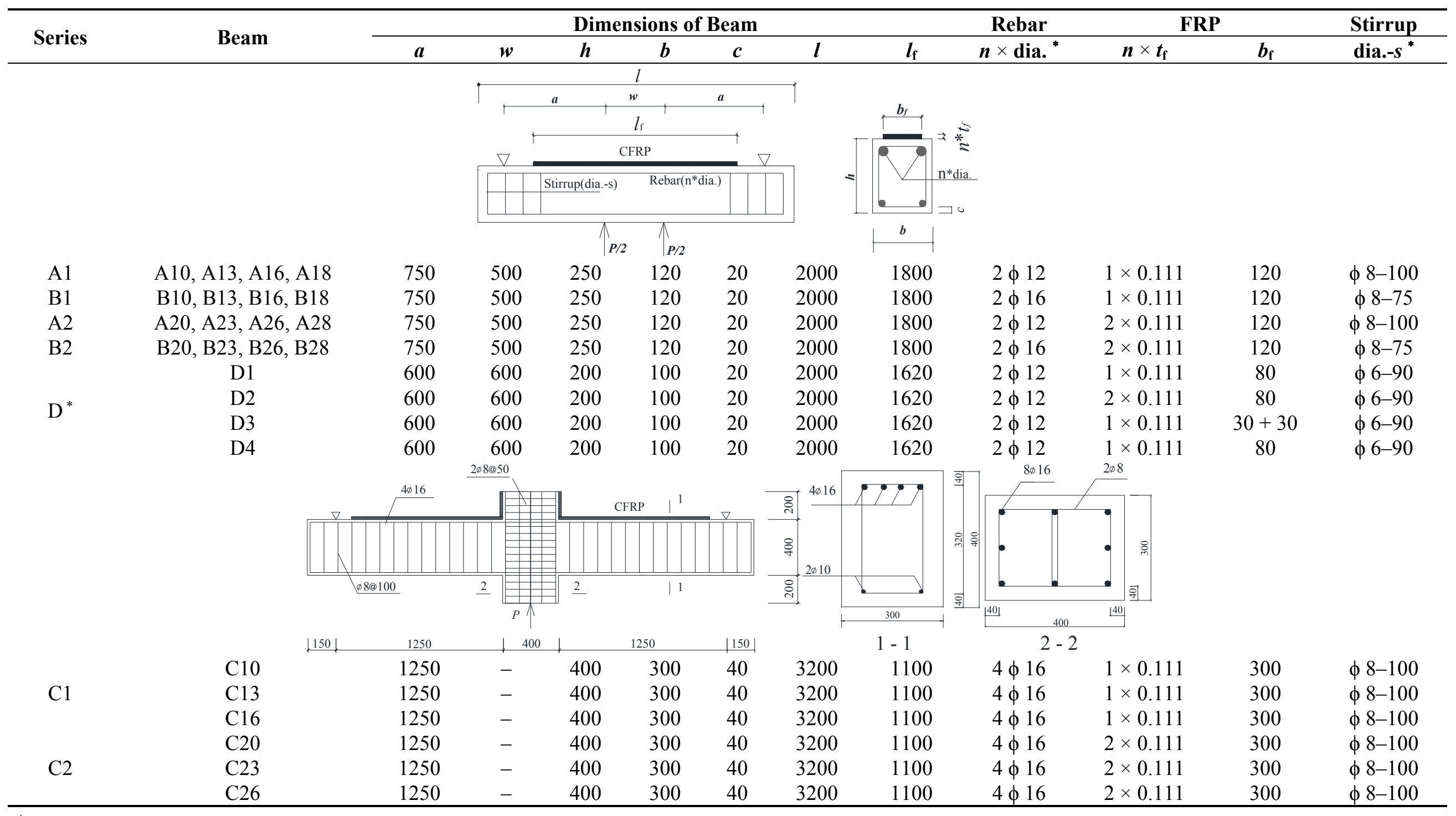

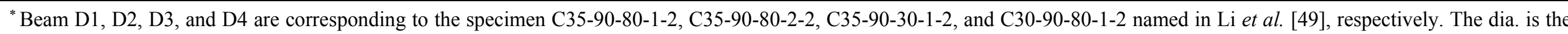
diameter of the rebar, and $s$ is the space between adjacent stirrups. 
Table 2. Material properties (MPa).

\begin{tabular}{lcccccccccc}
\hline \multirow{2}{*}{ Series } & \multicolumn{2}{c}{ Concrete } & \multicolumn{3}{c}{ Rebar } & \multicolumn{3}{c}{ Stirrup } & \multicolumn{2}{c}{ FRP } \\
\cline { 2 - 11 } & $\boldsymbol{f}_{\mathbf{c}}{ }^{*}$ & $\boldsymbol{f}_{\mathbf{t}}$ & $\boldsymbol{E}_{\mathbf{s}}$ & $\boldsymbol{f}_{\mathbf{y}}$ & $\boldsymbol{f}_{\mathbf{u}}$ & $\boldsymbol{E}_{\mathbf{s}}$ & $\boldsymbol{f}_{\mathbf{y v}}$ & $\boldsymbol{f}_{\mathbf{u}}$ & $\boldsymbol{E}_{\mathbf{f}}$ & $\boldsymbol{f}_{\mathbf{u}}$ \\
\hline $\mathrm{A} 1, \mathrm{~A} 2$ & 13.4 & 1.54 & 200,000 & 381 & 452 & 207,000 & 276 & 375 & 235,000 & 3,350 \\
$\mathrm{~B} 1, \mathrm{~B} 2$ & 16.7 & 1.78 & 200,000 & 381 & 452 & 207,000 & 276 & 375 & 235,000 & 3,350 \\
$\mathrm{C} 1, \mathrm{C} 2$ & 35.5 & 2.74 & 200,000 & 381 & 452 & 207,000 & 276 & 375 & 235,000 & 4,150 \\
D1, D2, D3 & 23.4 & 2.20 & 200,000 & 378 & 447 & 205,000 & 235 & 362 & 243,000 & 4,390 \\
D4 & 20.1 & 2.01 & 200,000 & 378 & 447 & 205,000 & 235 & 362 & 243,000 & 4,390 \\
\hline
\end{tabular}

${ }^{*} f_{\mathrm{c}}, f_{\mathrm{t}}$ are the compression and tensile strength of concrete; $E_{\mathrm{s}}, f_{\mathrm{y}}$, and $f_{\mathrm{u}}$ are Young's modulus, yielding strength, and ultimate strength of steel rebar; $E_{\mathrm{s}}, f_{\mathrm{yv}}$, and $f_{\mathrm{u}}$ are Young's modulus, yielding strength, and ultimate strength of stirrup; $E_{\mathrm{f}}$ and $f_{\mathrm{u}}$ are Young's modulus and ultimate strength of FRP reinforcement, respectively.

\section{Results and Discussion}

\subsection{Test Results}

The maximum bending moment and the shear force on the cross section of FRP-strengthened RC beam at initial debonding of FRP laminates are listed in Table 3.

There are 22 FRP-strengthened RC beams in series A1, A2, B1, B2, C1, and C2. 19 of them failed by IC debonding, their debonding process and characteristics are all the same. Taking beam A18 as an example, the debonding procedure and its characteristics are stated as follows.

The first flexural crack occurred when the applied load reached $10.0 \mathrm{kN}$. As the applied load was $31.7 \mathrm{kN}$, there are five flexural cracks developed at the constant moment region and eight flexure-shear cracks distributed at the shear spans and one of the flexure-shear cracks near the loading point became the critical flexure-shear crack (CFSC), as shown in Figure 2a. This applied load was constantly sustained, and FRP sheets were sequentially bonded on the tension face of RC beam. After the epoxy solidified, the test was continued. When the applied load reached $48.2 \mathrm{kN}$, the tension rebar yielded; the amount of cracks remains unchanged, but the width of the main flexural crack augmented slightly. Hereafter, the width of the CFSC was more pronounced with the increase of deflection. When the applied load reached $55.7 \mathrm{kN}$, one or two tributary cracks (TC) initiated in front of the CFSC towards the direction of decreasing moment, as shown in Figure $2 \mathrm{~b}$. The tributary cracks propagated towards the CFSC and intersected with it finally. In addition, the width of the TC was also increased with the increase of deflection, as shown in Figure 2c. When the applied load reached $60.6 \mathrm{kN}$, debonding initiated at the tip of the TC. Moreover, it can be clearly observed that the moment curvature of the shear span and the constant moment region were not in continuity, as shown in Figure $2 \mathrm{~d}$. As we know, the plastic hinge will be formed in the vicinity of the CFSC after tension rebar yielding. It can be observed in experimental tests that the crack space, crack width, and crack depth of flexure-shear cracks are all less than that of the flexural cracks. This indicates that the flexural stiffness of beam section at the shear span is higher than that at the constant moment region. As a result, the shear span of the beam will be rotated around the CFSC section leading to the discontinuity of moment curvature of $\mathrm{RC}$ beam left and right of the CFSC section, and was associated with the formation of relative vertical displacement between the two halves of the CFSC section. Figure 3 illustrates the relative vertical displacement between the two halves of the CFSC section. 
Table 3. Test results and statistical analysis results.

\begin{tabular}{|c|c|c|c|c|c|c|c|c|c|c|c|c|c|c|c|}
\hline \multirow{2}{*}{ Series } & \multirow{2}{*}{ Beam } & \multicolumn{2}{|c|}{ Tested Results } & \multicolumn{3}{|c|}{ Analyzed Results } & \multirow{2}{*}{$V_{\mathrm{n}} / V_{\mathrm{d}}$} & \multicolumn{2}{|c|}{$V_{\mathrm{n}} / V_{\mathrm{d}}$} & \multirow{2}{*}{$V_{\mathrm{n}} / V_{\mathrm{Mn}}$} & \multicolumn{2}{|c|}{$V_{\mathrm{n}} / V_{\mathrm{Mn}}$} & \multirow{2}{*}{$M_{\mathrm{d}} / M_{\mathrm{n}}$} & \multicolumn{2}{|c|}{$M_{\mathrm{d}} / M_{\mathrm{n}}$} \\
\hline & & ${ }^{*} M_{\mathrm{d}}$ & $V_{\mathrm{d}}$ & $M_{\mathrm{n}}$ & $V_{\mathrm{n}}$ & $V_{\mathrm{Mn}}$ & & $\mu$ & $\mathrm{CoV}$ & & $\mu$ & $\mathrm{CoV}$ & & $\mu$ & $\mathrm{CoV}$ \\
\hline \multirow{4}{*}{ A2 } & A20 & 24.9 & 33.2 & 23.5 & 81.3 & 31.4 & 2.45 & \multirow{4}{*}{2.43} & \multirow{4}{*}{$3.1 \%$} & 2.59 & \multirow{4}{*}{2.70} & \multirow{4}{*}{$3.2 \%$} & 1.06 & \multirow{4}{*}{1.11} & \multirow{4}{*}{$3.1 \%$} \\
\hline & $\mathrm{A} 23$ & 26.1 & 34.8 & 22.9 & 81.3 & 30.5 & 2.34 & & & 2.66 & & & 1.14 & & \\
\hline & A26 & 25.5 & 34.1 & 22.3 & 81.3 & 29.7 & 2.39 & & & 2.74 & & & 1.15 & & \\
\hline & $\mathrm{A} 28$ & 24.0 & 32.0 & 21.6 & 81.3 & 28.8 & 2.54 & & & 2.82 & & & 1.11 & & \\
\hline \multirow{4}{*}{ B2 } & $\mathrm{B} 20$ & 31.4 & 41.8 & 33.0 & 105.1 & 44.0 & 2.51 & \multirow{4}{*}{2.31} & \multirow{4}{*}{$6.0 \%$} & 2.39 & \multirow{4}{*}{2.45} & \multirow{4}{*}{$1.8 \%$} & 0.95 & \multirow{4}{*}{1.06} & \multirow{4}{*}{$6.6 \%$} \\
\hline & $\mathrm{B} 23$ & 36.2 & 48.3 & 32.5 & 105.1 & 43.3 & 2.18 & & & 2.43 & & & 1.11 & & \\
\hline & B26 & 36.0 & 48.1 & 32.0 & 105.1 & 42.6 & 2.19 & & & 2.47 & & & 1.13 & & \\
\hline & B28 & 33.6 & 44.8 & 31.5 & 105.1 & 42.0 & 2.35 & & & 2.51 & & & 1.07 & & \\
\hline \multirow{3}{*}{$\mathrm{C} 1$} & $\mathrm{C} 10$ & 136.5 & 109.2 & 155.0 & 223.4 & 124.0 & 2.05 & \multirow{3}{*}{2.19} & \multirow{3}{*}{$4.6 \%$} & 1.80 & \multirow{3}{*}{1.82} & \multirow{3}{*}{$0.6 \%$} & 0.88 & \multirow{3}{*}{0.83} & \multirow{3}{*}{$4.1 \%$} \\
\hline & $\mathrm{C} 13$ & 125.3 & 100.2 & 153.7 & 223.4 & 123.0 & 2.23 & & & 1.82 & & & 0.81 & & \\
\hline & C16 & 122.5 & 98.0 & 152.6 & 223.4 & 122.1 & 2.28 & & & 1.83 & & & 0.80 & & \\
\hline & $\mathrm{C} 20$ & 136.4 & 109.1 & 197.2 & 223.4 & 157.8 & 2.05 & & & 1.42 & & & 0.69 & & \\
\hline $\mathrm{C} 2$ & $\mathrm{C} 23$ & 136.4 & 116.5 & 194.7 & 223.4 & 155.8 & 1.92 & 1.96 & $3.2 \%$ & 1.43 & 1.43 & $1.0 \%$ & 0.75 & 0.73 & $4.0 \%$ \\
\hline & $\mathrm{C} 26$ & 145.6 & 116.8 & 192.6 & 223.4 & 154.0 & 1.91 & & & 1.45 & & & 0.76 & & \\
\hline & D1 & 15.8 & 26.3 & 16.0 & 61.2 & 26.6 & 2.33 & & & 2.30 & & & 0.99 & & \\
\hline $\mathrm{D}$ & D2 & 16.1 & 26.9 & 17.9 & 61.2 & 29.9 & 2.27 & 228 & $17 \%$ & 2.05 & 228 & $60 \%$ & 0.90 & 100 & $55 \%$ \\
\hline D & D3 & 16.1 & 26.9 & 15.4 & 61.2 & 25.6 & 2.28 & 2.28 & $1.1 \%$ & 2.39 & 2.28 & $6.0 \%$ & 1.05 & 1.00 & $0.5 \%$ \\
\hline & D4 & 16.1 & 26.9 & 16.0 & 59.8 & 26.6 & 2.27 & & & 2.37 & & & 1.07 & & \\
\hline
\end{tabular}

${ }^{*} M_{\mathrm{d}}, V_{\mathrm{d}}$ are the maximum bending moment and the shear force on the cross section of FRP-strengthened RC beam at initial debonding of FRP laminates, $M_{\mathrm{n}}, V_{\mathrm{n}}$ are the nominal flexural strength and shear strength of RC beam, $V_{\mathrm{Mn}}$ is the shear force on the cross section as RC beam reaches its nominal flexural strength $M_{\mathrm{n}}, \mu$ is the average of statistical variable, and $\mathrm{CoV}$ is the coefficient of variation of the statistical variable. 
Figure 2. Debonding process and characteristics of beam A18 (a) Flexural cracks (FC-1-FC-5) and critical flexure-shear crack (CFSC). (b) Tributary crack (TC) generated near the tip of CFSC. (c) Debonding initiated at the tip of TC and deflection discontinuity left and right of the CFSC section. (d) Deflection discontinuity left and right of the CFSC section is very clear after FRP laminates totally debonded from concrete substrate.

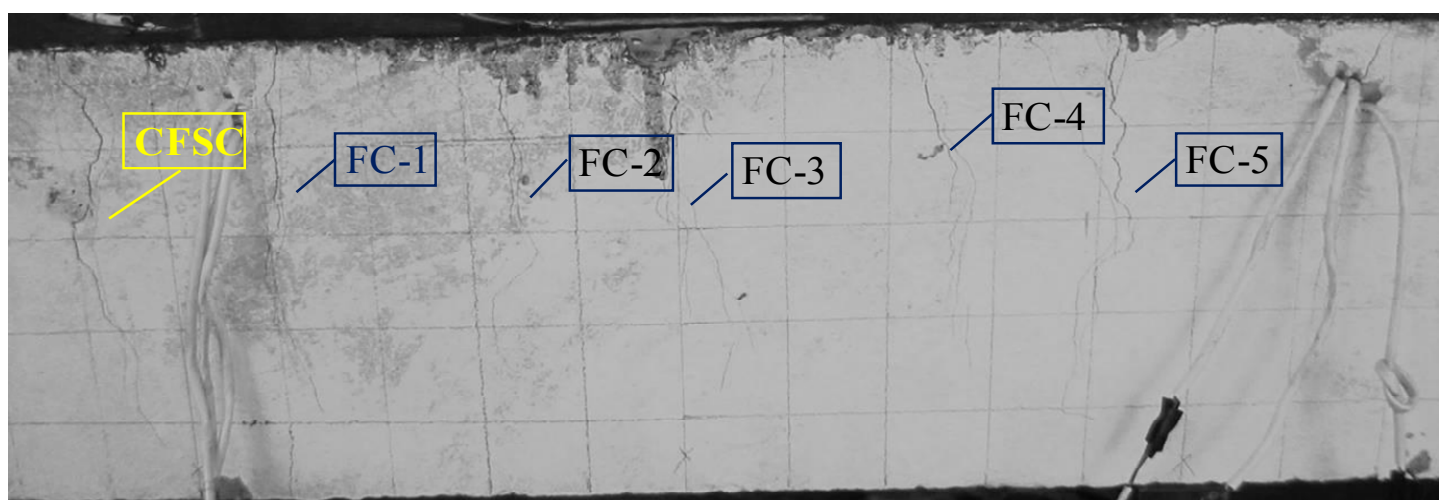

(a)

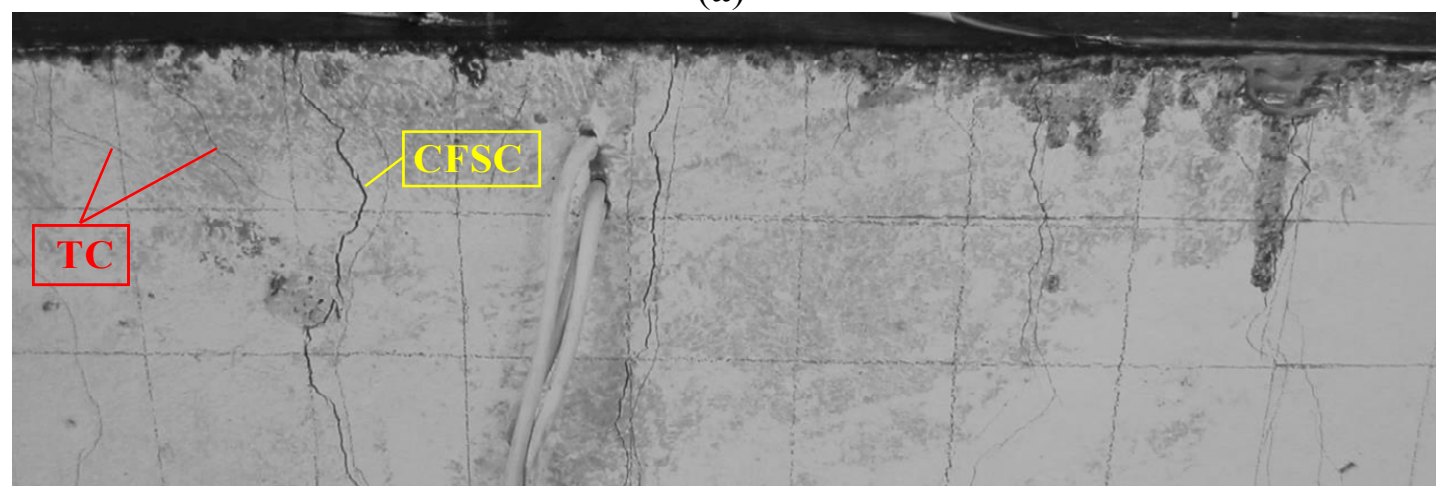

(b)

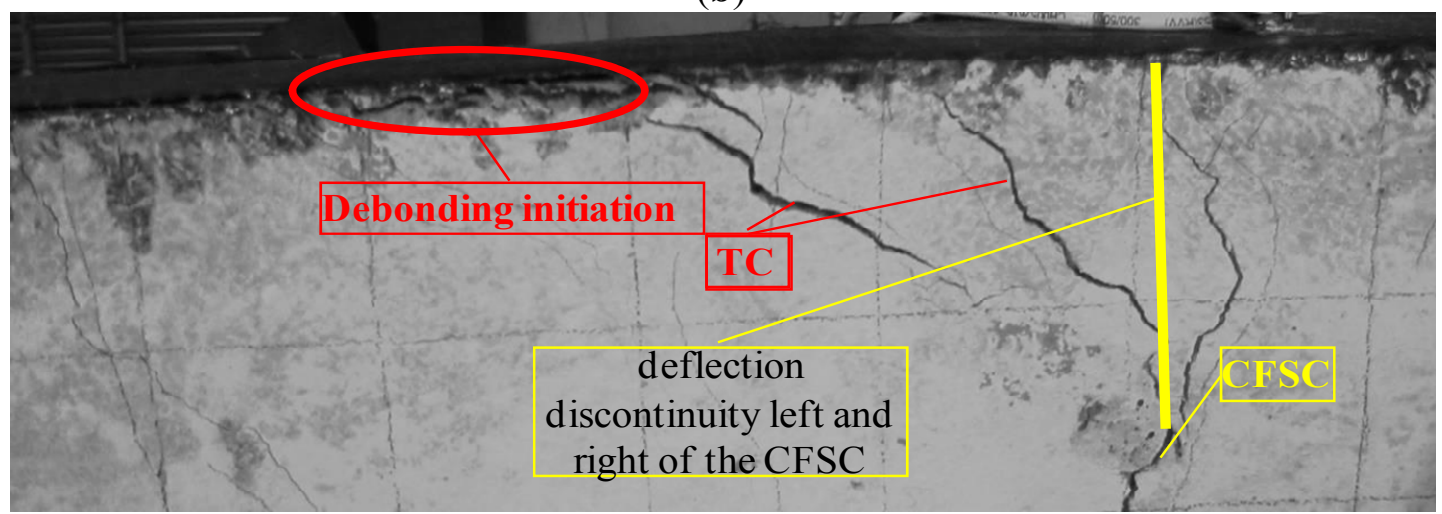

(c)

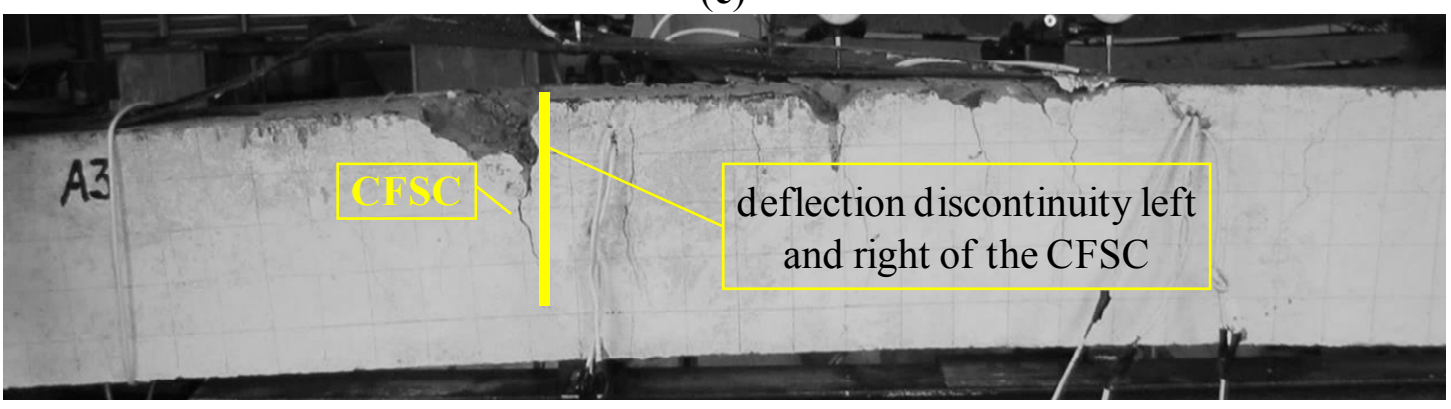

(d) 
Figure 3. Relative vertical displacement between two sides of the main crack [44-46].

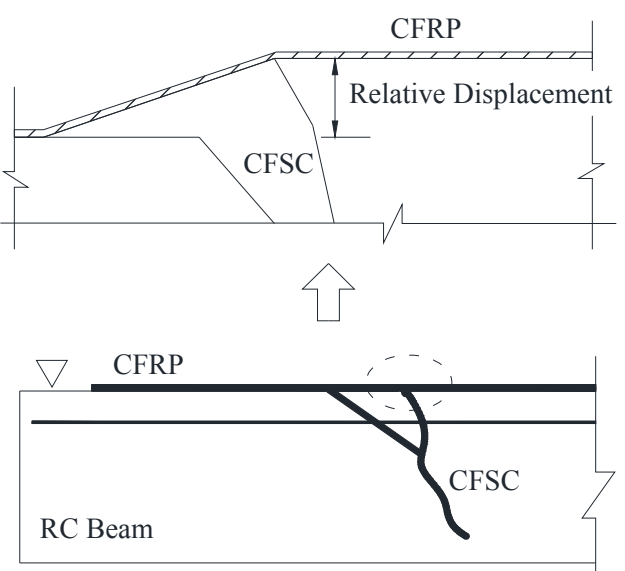

It was observed during the test that the earlier initiation and more opening-up of CFSC, the earlier development of tributary cracks and the debonding of CFRP laminate. The present experimental results proved further that the shear resistance has an important effect on FRP debonding.

As it is well-known, the shear resistance of the beam section plays the key role in the opening-up of the CFSC and the relative vertical displacement between the two halves of the CFSC section. The greater the CFSC was opening-up, the greater the tensile stress concentrated in FRP composites, and the greater the shear stress produced on the FRP-concrete interface. Moreover, the relative vertical displacement between the two halves of the CFSC section makes the FRP composites produce normal tensile stress on the concrete substrate. Both the increase of the shear stress on the FRP-concrete interface and the normal tensile stress on the concrete substrate will promote the debonding of FRP laminates. Therefore, it can be concluded qualitatively that the shear capacity of RC beam plays a key role in debonding failure of RC beams flexurally strengthened with externally bonded FRP composites.

\subsection{Influence of Shear Resistance of RC Beam on Flexural Debonding Load-Carrying Capacity}

In addition to the test results of series A2, B2, C1, and C2, the test results of series D carried out by Li et al. [49] are also analyzed as a supplement of the limited test results. All the strengthened beams in series D failed by IC debonding. The dimensions and materials properties of series D are listed in Tables 1 and 2.

Whether the flexural failure or the shear failure depend on the internal forces, that is, the bending moment and the shear force, on the cross section of RC beam. To make the analytical results of the influence of shear resistance on flexural debonding load-carrying capacity of FRP-strengthened RC beams comparable, the ratio of nominal shear strength $V_{\mathrm{n}}$ to shear force $V_{\mathrm{d}}$ on the critical section at initial debonding, $V_{\mathrm{n}} / V_{\mathrm{d}}$, was used. Similarly, to make the analytical results comparable in evaluating the flexural debonding load-bearing capacity, the ratio of tested debonding bending moment $M_{\mathrm{d}}$ to the nominal flexural strength $M_{\mathrm{n}}$ of the strengthened beam, $M_{\mathrm{d}} / M_{\mathrm{n}}$, was used. Then, the influence of shear resistance $V_{\mathrm{n}} / V_{\mathrm{d}}$ on flexural debonding load-bearing capacity $M_{\mathrm{d}} / M_{\mathrm{n}}$ was analyzed based on the test results. The nominal shear strength and flexural strength of FRP-strengthened RC beams are calculated according to the conventional RC theory.

The nominal shear strength of RC beam is calculated by the formula provided by GB20010-2010 [50]: 


$$
V_{\mathrm{n}}=\frac{1.75}{\lambda+1} f_{\mathrm{t}} b d_{0}+f_{\mathrm{yv}} \frac{A_{\mathrm{sv}}}{s} d_{0}
$$

Where, $f_{\mathrm{t}}$ is the tensile strength of concrete; $f_{\mathrm{yv}}$ is the yield strength of stirrup steel, $b$ and $d_{0}$ are the width and effective depth of beam section, $\lambda$ is the depth-span ratio of beam, $s$ is the spacing of shear reinforcement, and $A_{\mathrm{sv}}$ is the total cross-sectional area of stirrup within a distance $s$, respectively.

The nominal flexural strength of FRP-strengthened RC beam is calculated by provisions in ACI440-08 [29]:

$$
M_{\mathrm{n}}=A_{\mathrm{s}} f_{\mathrm{y}}\left(d-\frac{\beta_{1} c}{2}\right)+A_{\mathrm{f}} f_{\mathrm{fe}}\left(d-\frac{\beta_{1} c}{2}\right)
$$

Where, $A_{\mathrm{s}}$ and $A_{\mathrm{f}}$ are the total cross-sectional area of tension steel and FRP reinforcements, $d$ is the total depth of beam cross-section, $c$ is the distance from the outer compressive fiber to the neutral axis, $\phi_{1}$ is a constant that is a function of the compressive strength of concrete, $f_{\mathrm{y}}$ is the yield strength of tension steel, and $f_{\mathrm{fe}}$ is the effective tensile stress in FRP reinforcement, and:

$$
\begin{gathered}
f_{\mathrm{fe}}=E_{\mathrm{f}} \varepsilon_{\mathrm{fe}} \\
\varepsilon_{\mathrm{fe}}=\varepsilon_{\mathrm{cu}}\left(\frac{d-c}{c}\right)-\varepsilon_{\mathrm{bi}}
\end{gathered}
$$

Where, $E_{\mathrm{f}}$ is the modulus of elasticity of FRP composite, $\varepsilon_{\mathrm{fe}}$ is the effective tensile strain in FRP reinforcement, $\varepsilon_{\mathrm{cu}}$ is the ultimate compressive strain of concrete, and $\varepsilon_{\mathrm{bi}}$ is the initial strain level on the bonded substrate, it can be determined from an elastic analysis of the existing member, considering all loads that will be on the member during the installation of the FRP system.

Table 3 summarizes the maximum bending moment $M_{\mathrm{d}}$ and the shear force $V_{\mathrm{d}}$ on the cross section of FRP-strengthened beam at initial debonding of FRP laminates, the nominal flexural strength $M_{\mathrm{n}}$ and shear strength $V_{\mathrm{n}}$, and the shear force $V_{M \mathrm{n}}$ on the cross section as the RC beam reaches its nominal flexural strength $M_{\mathrm{n}}$.

Their average $\mu$ and coefficient of variation $\mathrm{CoV}$ of $V_{\mathrm{n}} / V_{\mathrm{d}}, V_{\mathrm{n}} / V_{M \mathrm{n}}$ and $M_{\mathrm{d}} / M_{\mathrm{n}}$ were analyzed and summarized in Table 3.

The averages of $M_{\mathrm{d}} / M_{\mathrm{n}}$ of series A2, B2, C1, C2, and D are 1.11, 1.06, 0.83, 0.73, and 1.00, with coefficients of variation of $3.1 \%, 6.6 \%, 4.1 \%, 4.0 \%$, and $6.5 \%$, respectively. The averages of $V_{\mathrm{n}} / V_{\mathrm{d}}$ of series A2, B2, C1, C2, and D are 2.43, 2.31, 2.19, 1.96, and 2.28, with coefficients of variation of $3.1 \%, 6.0 \%, 4.6 \%, 3.2 \%$, and $1.7 \%$, respectively. Figure 4 shows the relationship between $M_{\mathrm{d}} / M_{\mathrm{n}}$ and $V_{\mathrm{n}} / V_{\mathrm{d}}$, their goodness of linear fit $R^{2}$ is 0.9134 . This indicates that $M_{\mathrm{d}} / M_{\mathrm{n}}$ and $V_{\mathrm{n}} / V_{\mathrm{d}}$ have a good linear relationship. When $V_{\mathrm{n}} / V_{\mathrm{d}}$ is $1.96, M_{\mathrm{d}} / M_{\mathrm{n}}$ is 0.73 . However, $M_{\mathrm{d}} / M_{\mathrm{n}}$ is 1.11 as $V_{\mathrm{n}} / V_{\mathrm{d}}$ is 2.43 . It is obviously that the flexural debonding load-carrying capacity is significantly increased with the increase of $V_{\mathrm{n}} / V_{\mathrm{d}} . M_{\mathrm{d}} / M_{\mathrm{n}}$ is only 0.73 as $V_{\mathrm{n}} / V_{\mathrm{d}}$ is 1.96 , this indicates that debonding failure will be initiated when the bending moment $M_{\mathrm{d}}$ on the cross section is much lower than its nominal flexural strength $M_{\mathrm{n}}$. However, when $V_{\mathrm{n}} / V_{\mathrm{d}}$ is greater than 2.28, the ratios of $M_{\mathrm{d}} / M_{\mathrm{n}}$ are all greater than 1.0, this implies that debonding failure will not occur when the bending moment on the cross section reaches the nominal flexural strength of FRP-strengthened RC beam. Therefore, it can be concluded that the shear resistance of RC beam has a great effect on flexural debonding load-carrying capacity of 
FRP-strengthened RC beam. As a result, the influence of shear resistance on flexural debonding load-carrying capacity must be fully considered in the flexural strengthening design of RC beams.

Figure 4. Relationship between $V_{\mathrm{n}} / V_{\mathrm{d}}$ and $M_{\mathrm{d}} / M_{\mathrm{n}}$.

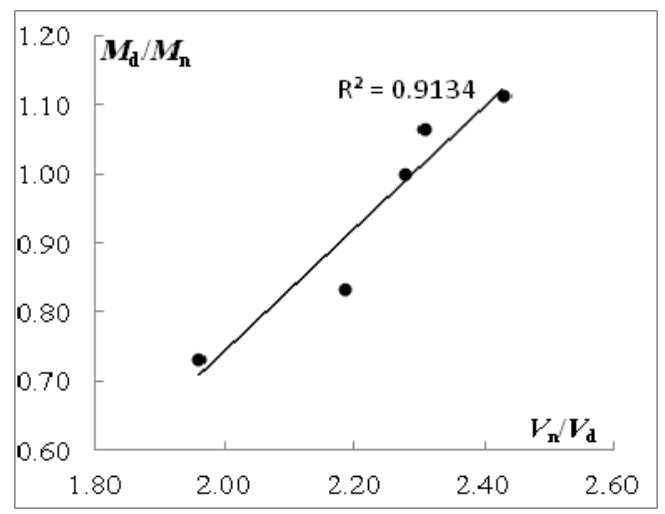

However, the shear force $V_{\mathrm{d}}$ on the cross section cannot be determined in flexural strengthening design of RC beams. Consequently, the relationship between $V_{\mathrm{n}} / V_{\mathrm{d}}$ and $M_{\mathrm{d}} / M_{\mathrm{n}}$ cannot be used in flexural strengthening design. In order to take the influence of shear resistance on flexural debonding load-carrying capacity into account in flexural strengthening design of RC beam, the shear force $V_{M \mathrm{n}}$ which is the shear force on the cross section as RC beam reaches its nominal flexural strength $M_{\mathrm{n}}$ substituting for $V_{\mathrm{d}}$ was employed to analyze the relationship between $V_{\mathrm{n}} / V_{M \mathrm{n}}$ and $M_{\mathrm{d}} / M_{\mathrm{n}}$. Table 3 shows the statistical analysis results. The averages of $V_{\mathrm{n}} / V_{M \mathrm{n}}$ of series $\mathrm{A} 2, \mathrm{~B} 2, \mathrm{C} 1, \mathrm{C} 2$, and $\mathrm{D}$ are 2.70 , $2.45,1.82,1.43$, and 2.28 , with coefficients of variation of $3.2 \%, 1.8 \%, 0.6 \%, 1.0 \%$, and $6.0 \%$, respectively. Figure 5 shows the relationship between $M_{\mathrm{d}} / M_{\mathrm{n}}$ and $V_{\mathrm{n}} / V_{\mathrm{Mn}}$, their goodness of linear fit $R^{2}$ is 0.9919 . This indicates that $M_{\mathrm{d}} / M_{\mathrm{n}}$ and $V_{\mathrm{n}} / V_{M \mathrm{n}}$ have a very good linear relationship and have the same variation tendency as $V_{\mathrm{n}} / V_{\mathrm{d}}$ and $M_{\mathrm{d}} / M_{\mathrm{n}}$. Therefore, the relationship between $M_{\mathrm{d}} / M_{\mathrm{n}}$ and $V_{\mathrm{n}} / V_{M \mathrm{n}}$ can also be used in evaluating the influence of shear resistance on flexural debonding load-carrying capacity, and thus provides support for flexural strengthening design. According to the statistical analysis results of $M_{\mathrm{d}} / M_{\mathrm{n}}$ and $V_{\mathrm{n}} / V_{M \mathrm{n}}$, when $V_{\mathrm{n}} / V_{M \mathrm{n}}$ is greater than 2.28, the ratios of $M_{\mathrm{d}} / M_{\mathrm{n}}$ are all greater than 1.0 . Therefore, it is suggested that $V_{\mathrm{n}} / V_{M \mathrm{n}}$ should not be less than 2.3. This limitation ensures that debonding of FRP reinforcements will not be initiated as FRP-strengthened RC beam reaches its nominal flexural strength.

Figure 5. Relationship between $M_{\mathrm{d}} / M_{\mathrm{n}}$ and $V_{\mathrm{n}} / V_{M \mathrm{n}}$.

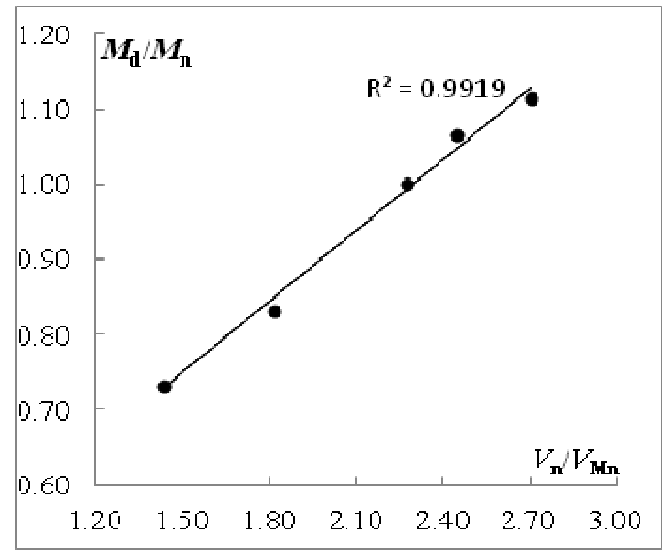




\section{Conclusions}

This present study investigates and analyzes the effect of shear resistance on flexural debonding load-carrying capacity of FRP-strengthened RC beams based on the test results. Within the scope of the limited experimental results, the following conclusions can be drawn from this study:

- The shear resistance of RC beam has a great effect on flexural debonding load-carrying capacity of FRP-strengthened RC beam. The influence of shear resistance on flexural debonding load-carrying capacity must be fully considered in flexural strengthening design of $\mathrm{RC}$ beams.

- $M_{\mathrm{d}} / M_{\mathrm{n}}$ and $V_{\mathrm{n}} / V_{\mathrm{d}}$ have a good linear relationship. The flexural debonding load-carrying capacity is significantly increased with the increase of $V_{\mathrm{n}} / V_{\mathrm{d}}$. The goodness of the linear fit of $M_{\mathrm{d}} / M_{\mathrm{n}}$ and $V_{\mathrm{n}} / V_{M \mathrm{n}}$ is better than that of $M_{\mathrm{d}} / M_{\mathrm{n}}$ and $V_{\mathrm{n}} / V_{\mathrm{d}}$, and their variation tendency is the same. Therefore, the relationship between $M_{\mathrm{d}} / M_{\mathrm{n}}$ and $V_{\mathrm{n}} / V_{M \mathrm{n}}$ can also be used in evaluating the influence of shear resistance on flexural debonding load-carrying capacity, and also provides support for flexural strengthening design. It is suggested that $V_{\mathrm{n}} / V_{M \mathrm{n}}$ should not be less than 2.3 in order to prevent debonding failure of FRP reinforcements as FRP-strengthened RC beam reaches its nominal flexural strength.

- The existing debonding models were developed based on the single-shear test results. However, the experimental results proved that the shear resistance of RC beam plays the key role in FRP debonding failure. Consequently, the influence of shear resistance of RC beam on FRP debonding failure must be fully considered in developing the debonding criteria and model.

- Presently, only a few of experimental studies have been carried out against investigating the influence of shear resistance on flexural debonding load-carrying capacity of FRP-strengthened $\mathrm{RC}$ beams. This vital issue, which remains under investigated, must be given the attention it deserves through further experimental and analytical studies.

\section{Acknowledgments}

The authors wish to acknowledge the staff members in the Structure Laboratory of Zhejiang University for their necessary support to carry out the tests. We would also like to express our gratitude to the following graduate students Xiaolong Xu, Jin Zhou, and Dengfeng Zhou, for their assistance in conducting the experimental phases of this study and to thank the reviewers for their careful review and constructive suggestions and to thank the Assistant Manager Jingjing Yang for her careful editing with regard to our manuscript.

This research project has been partially funded by the science and technology development foundation for college and university in Shanghai (03HK03).

\section{Author Contributions}

Guibing $\mathrm{Li}$ is responsible for performing the mechanical tests and has contributed to the writing of all the sections within the paper. Aihui Zhang is working on directing the mechanical tests and has been in charge of writing the results and discussion and conclusions sections to analyze the results. Weiliang Jin is responsible for the research project. 


\section{Conflicts of Interest}

The authors declare no conflict of interest.

\section{References}

1. Teng, J.G.; Smith, S.T.; Yao, J.; Chen, J.F. Intermediate crack-induced debonding in RC beams and slabs. Constr. Build. Mater. 2003, 17, 447-462.

2. Hosseini, A.; Mostofinejad, D. Effective bond length of FRP-to-concrete adhesively-bonded joints: Experimental evaluation of existing models. Int. J. Adhes. Adhes. 2014, 48, 150-158.

3. Chen, J.; Teng, J. Anchorage strength models for FRP and steel plates bonded to concrete. J. Struct. Eng. 2001, 127, 784-791.

4. Khalifa, A.; Gold, W.; Nanni, A.; Abdel-Aziz, M.I. Contribution of externally bonded FRP to shear capacity of RC flexural members. J. Compos. Constr. 1998, 2, 195-202.

5. Dai, J.; Ueda, T.; Sato, Y. Development of the nonlinear bond stress-slip model of fiber reinforced plastics sheet-concrete interfaces with a simple method. J. Compos. Constr. 2005, 9, 52-62.

6. Seracino, R.; Raizal Saifulnaz, M.; Oehlers, D. Generic debonding resistance of EB and NSM plate-to-concrete joints. J. Compos. Constr. 2007, 11, 62-70.

7. Yuan, H.; Wu, Z.S. Interfacial fracture theory in structures strengthened with composite of continuous fiber. In Proceedings of the Symposium of China and Japan, science and technology of the 21st century, Tokyo, Japan, 13-15 September 1999; pp. 142-155.

8. Yuan, H.; Wu, Z.S.; Yoshizawa, H. Theoretical solution on interfacial stress transfer of externally bonded steel/composite laminates. J. Struct. Eng. Earthq. Eng. 2001, 18, 27-39.

9. Wu, Y.-F.; Xu, X.-S.; Sun, J.-B.; Jiang, C. Analytical solution for the bond strength of externally bonded reinforcement. Compos. Struct. 2012, 94, 3232-3239.

10. Yuan, H.; Lu, X.; Hui, D.; Feo, L. Studies on FRP-concrete interface with hardening and softening bond-slip law. Compos. Struct. 2012, 94, 3781-3792.

11. Kim, Y.; Harries, K. Statistical characterization of reinforced concrete beams strengthened with FRP sheets. J. Compos. Constr. 2013, 17, 357-370.

12. Kalfat, R.; Al-Mahaidi, R.; Smith, S. Anchorage devices used to improve the performance of reinforced concrete beams retrofitted with FRP composites: State-of-the-art review. J. Compos. Constr. 2013, 17, 14-33.

13. Pesic, N.; Pilakoutas, K. Concrete beams with externally bonded flexural FRP-reinforcement: Analytical investigation of debonding failure. Compos. B Eng. 2003, 34, 327-338.

14. Bilotta, A.; Ludovico, M.D.; Nigro, E. FRP-to-concrete interface debonding: Experimental calibration of a capacity model. Compos. B Eng. 2011, 42, 1539-1553.

15. Radfar, S.; Foret, G.; Saeedi, N.; Sab, K. Simulation of concrete cover separation failure in FRP plated RC beams. Constr. Build. Mater. 2012, 37, 791-800.

16. Chen, J.F.; Yuan, H.; Teng, J.G. Debonding failure along a softening FRP-to-concrete interface between two adjacent cracks in concrete members. Eng. Struct. 2007, 29, 259-270.

17. Finckh, W.; Zilch, K. Strengthening and rehabilitation of reinforced concrete slabs with carbon-fiber reinforced polymers using a refined bond model. Comput. Aided Civ. Infrastruct. Eng. 2012, 27, 333-346. 
18. Lu, X.Z.; Teng, J.G.; Ye, L.P.; Jiang, J.J. Intermediate crack debonding in FRP-strengthened RC beams: FE analysis and strength model. J. Compos. Constr. 2007, 11, 161-174.

19. Oehlers, D.J.; Liu, I.; Seracino, R. A generic design approach for EB and NSM longitudinally plated RC beams. Constr. Build. Mater. 2007, 21, 697-708.

20. Oller Ibars, E.; Cobo del Arco, D.; Marí Bernat, A. Design proposal to avoid peeling failure in FRP-strengthened reinforced concrete beams. J. Compos. Constr. 2009, 13, 384-393.

21. Said, H.; $\mathrm{Wu}, \mathrm{Z}$. Evaluating and proposing models of predicting IC debonding failure. J. Compos. Constr. 2008, 12, 284-299.

22. Wu, Z.S.; Niu, H.D. Prediction of crack-induced debonding failure in R/C structures flexurally strengthened with externally bonded FRP composites. JSCE J. Mater. Concr. Struct. Pavements 2007, 63, 620-639.

23. Bilotta, A.; Faella, C.; Martinelli, E.; Nigro, E. Design by testing procedure for intermediate debonding in EBR FRP strengthened RC beams. Eng. Struct. 2013, 46, 147-154.

24. Externally Bonded FRP Reinforcement for RC Structures; fib Bulletin No. 14; Technical Report on the Design and Use of Externally Bonded Fibre Reinforced Polymer Reinforcement (FRP EBR) for Reinforced Concrete Structures: Lausanne, Switzerland, 2001; pp 51-58.

25. Maruyama, K. Recommendatios for Upgrading of Concrete Structures with Use of Continuous Fiber Sheets; Nagaoka University of Technology: Nagaoka, Japan, 2001; p. 88.

26. Design Guidance on Strengthening Concrete Structures Using Fiber Composite Materials, 2nd ed.; Concrete Society Technical Report No.55: London, UK, 2004.

27. Guidelines for Design, Execution and Control of Strengthening Interventions by Means of Fibre-Reinforced Composites-Materials, Reinforced Concrete and Prestressed Concrete Structures, Masonry Structures; CNR DT200; National Research Council, Advisory Committee on Technical Regulations for Constructions: Rome, Italy, 2004; p. 164.

28. Lee, D.; Cheng, L. Bond of NSM systems in concrete strengthening-Examining design issues of strength, groove detailing and bond-dependent coefficient. Constr. Build. Mater. 2013, 47, 1512-1522.

29. Guide for the Design and Construction of Externally Bonded FRP Systems for Strengthening Concrete Structures; ACI-440.2R-08; American Concrete Institute (ACI): Farmington Hills, MI, USA, 2008; p. 76.

30. Hassan, T.; Rizkalla, S. Investigation of bond in concrete structures strengthened with near surface mounted carbon fiber reinforced polymer strips. J. Compos. Constr. 2003, 7, 248-257.

31. Oehlers, D.; Haskett, M.; Wu, C.; Seracino, R. Embedding NSM FRP plates for improved IC debonding resistance. J. Compos. Constr. 2008, 12, 635-642.

32. Mohamed Ali, M.S.; Oehlers, D.J.; Griffith, M.C.; Seracino, R. Interfacial stress transfer of near surface-mounted FRP-to-concrete joints. Eng. Struct. 2008, 30, 1861-1868.

33. Hassan, T.K.; Rizkalla, S.H. Bond mechanism of near-surface-mounted fiberreinforced polymer bars for flexural strengthening of concrete structures. ACI Struct. J. 2004, 101, 830-839.

34. Recommendations for Updating of Concrete Structures with Use of Continuous Fiber Sheets, Concrete Engineering Series 41; Japan Society of Civil Engineers: Tokyo, Japan, 2001; pp. 31-34. 
35. Toutanji, H.; Ueno, S.; Vuddandam, R. Prediction of the interfacial shear stress of externally bonded FRP to concrete substrate using critical stress state criterion. Compos. Struct. 2013, 95, 375-380.

36. Büyükoztürk, O.; Gunes, O.; Karaca, E. Characterization and modeling of debonding in RC beams strengthened with FRP composites. In Proceedings of the 15th ASCE Engineering Mechanics Conference, Columbia University, New York, NY, USA, 2-5 June 2002; pp. 1-8.

37. Garden, H.N.; Quantrill, R.J.; Hollaway, L.C.; Thorne, A.M.; Parke, G.A.R. An experimental study of the anchorage length of carbon fiber composite plates used to strengthen reinforced concrete beams. Constr. Build. Mater. 1998, 12, 203-219.

38. Garden, H.N.; Hollaway, L.C. An experimental study of the influence of plate end anchorage of carbon fibre composite plates used to strengthen reinforced concrete beams. Compos. Struct. 1998, 42, 175-188.

39. Rabinovitch, O.; Frostig, Y. Experiments and analytical comparison of RC beams strengthened with CFRP composites. Compos. B Eng. 2003, 34, 663-677.

40. Pham, H.; Al-Mahaidi, R. Experimental investigation into flexural retrofitting of reinforced concrete bridge beams using FRP composites. Compos. Struct. 2004, 66, 617-625.

41. Pham, H.; Al-Mahaidi, R. Prediction models for debonding failure loads of carbon fiber reinforced polymer retrofitted concrete beams. J. Compos. Constr. 2006, 10, 48-59.

42. Zhang, A.H.; Jin, W.L.; Li, G.B. Behavior of preloaded RC beams strengthened with CFRP laminates. J. Zhejiang Univ. Sci. A 2006, 7, 436-444.

43. Yang, Y.X.; Yue, Q.R.; Ye, L.P.; Hu, Y.C. Debonding failure of reinforced concrete beams strengthened with carbon fiber sheets. Eng. Mech. 2004, 21, 150-156.

44. Yao, J.; Teng, J.G.; Chen, J.F. Experimental study on FRP-to-concrete bonded joints. Compos. B Eng. 2005, 36, 99-113.

45. Pan, J.; Leung, C.K.Y. Debonding along the FRP-concrete interface under combined pulling/peeling effects. Eng. Fract. Mech. 2007, 74, 132-150.

46. Pan, J. Crack-Induced Debonding Failure in Fiber Reinforced Plastics (FRP) Strengthened Concrete Beams: Experimental and Theoretical Analysis. Ph.D. Thesis, Hongkong University of Science and Technology, Hongkong, China, 17 September 2005.

47. Teng, J.G.; Chen, J.F.; Smith, S.T.; Lam, L. FRP-Strengthened RC Structures; John Wiley and Sons: Hoboken, NJ, USA, 2002; p. 246.

48. Li, G. Study on Flexural Behavior and Deboding Failure of CFRP-Strengthened RC Beams. Ph.D. Thesis, Zhejiang University, Hangzhou, China, 23 May 2006.

49. Li, Y.; Liu, Z.; Hu, C. Research on shear stress of debonding plate-end of RC beam strengthened with CFRP. J. Henan Polytech. Uni. Nat. Sci. 2007, 26, doi:10.3969/j.issn.1673-9787.2007.06.018.

50. Ministry of Housing and Urban-Rural Development PRC, Code for Design of Concrete Structures; China Achitecture \& Building Press: Beijing, China, 2010; p. 425.

(C) 2014 by the authors; licensee MDPI, Basel, Switzerland. This article is an open access article distributed under the terms and conditions of the Creative Commons Attribution license (http://creativecommons.org/licenses/by/3.0/). 